\title{
DISTRIBUTED SPACECRAFT MISSIONS (DSM) TECHNOLOGY DEVELOPMENT AT NASA GODDARD SPACE FLIGHT CENTER
}

\author{
Jacqueline Le Moigne \\ NASA Goddard Space Flight Center, Greenbelt, MD 20771
}

\begin{abstract}
For the last 5 years, NASA Goddard has been investigating Distributed Spacecraft Missions (DSM) system architectures, surveying past, current and potential mission concepts, developing several taxonomies and identifying some key technologies that will enable future DSM mission design, development, operations and management. This paper summarizes this Initiative and the talk will provide details about specific Goddard DSM projects that are currently underway and that are relevant to future Earth Science missions.
\end{abstract}

Index Terms - Distributed Spacecraft Missions (DSM), Constellations, Precision Formation Flying

\section{INTRODUCTION}

A "Distributed Spacecraft Mission (DSM)" is a mission that involves multiple spacecraft to achieve one or more common goals. Multipoint measurement missions can provide a significant advancement in science return, and this science interest coupled with many recent technological advances is driving a growing trend in implementing future NASA missions as DSMs.

To achieve an understanding of Earth- and spaceprocesses requires using large amounts of complementary measurements in space and time. But, since the concept of distributed missions was first introduced in the early 2000 's (e.g., [1] to [5]), mainly in the Earth Science domain, it has not been systematically traded when designing main stream missions. It has only been considered when it was the solution to satisfy some given science requirements (e.g., for the GRACE or the MMS concepts). This gap of more than 10 years in a systematic interest in DSM is probably explained by the cost and potentially the complexity associated with such missions. The high costs that were estimated for potential DSM were often the consequence of constellation designs based on repeating $n$ times the design and the building of one spacecraft, therefore leading to costs being $n$ times the cost of a monolithic mission. Additionally, cost models that have been developed for monolithic missions do not take into account cost savings associated with economies of scale and with risk minimization when dealing with DSM. On the other hand, it is true that building a distributed mission adds to the complexity of the mission, not only in the development phase but also in the operational phase, and this complexity translates into additional costs and risk to the mission. Therefore, it is only now that new technologies and capabilities such as smallsats, cubesats, hosted payloads, onboard computing, better space communications, and ground systems automation have appeared and became mature, that DSM seem to be feasible for a reasonable and potentially lower cost and risk than monolithic missions.

The objective of the Goddard Initiative is to make marked and demonstrable progress in developing and/or maturing the technologies that will be necessary to design, develop, launch and operate DSMs. The DSM activity is a multi-year project-level initiative that targets delivery, integration, and demonstration of missionenabling technologies and key capabilities that will significantly advance the spatial, spectral, temporal, and angular resolution of Earth and space science observations. In this paper, we will first define some general DSM terms, then we will review some of the main past and current distributed missions, along with a few potential future concepts or measurements that would take advantage of DSM. Finally, we will present a few DSM projects currently in development at NASA Goddard.

\section{SOME DEFINITIONS AND TAXONOMIES}

While a general "Distributed Spacecraft Mission (DSM)" has been defined in section 1, a DSM can be defined from inception and we call it a "Constellation", or it can become a DSM after the fact, in which case we will call it an "ad-hoc" DSM or a "Virtual" mission. For all these types of DSM, we do not assume the spacecraft to be of any specific sizes, i.e., we do not restrict this study to CubeSats or SmallSats, although lowering cost considerations will involve choosing smaller spacecraft. In the remaining of this paper, we will refer to "CubeSat" as the class of satellites smaller than $10 \mathrm{kgs}$, "MicroSat" between 10 and $100 \mathrm{~kg}$ and "MiniSat" from 100 to $180 \mathrm{~kg}$.

In our general definition of DSM, we purposely did not specify if the multiple spacecraft were launched together, if they were achieving the common goals by design or in an ad-hoc fashion, or if the common goals 
were scientific or not. In order to derive this terminology, various DSM characteristics are considered and their different instantiations are classified in a first taxonomy described in Table 1 . These different levels of details are embedded in the definitions described in [6] and in an internal Goddard report. Example descriptions related to DSM appearance (TAB 1.1) are given below:

\section{TAB 1.1.1 Constellations}

\section{Constellation}

A reference to a space mission that, beginning with its inception, is composed of two or more spacecraft that are placed into specific orbit(s) for the purpose of serving a common objective (e.g., MMS or Iridium).

\section{Reconfigurable constellation}

A constellation that possesses the ability to change one of more intrinsic characteristics while on orbit. Some of these characteristics may include any or all of the followings: orbit, attitude, relative spacing, observing activity coordination with other spacecraft, number of spacecraft and other TBD characteristics (e.g., MMS).

\section{Homogeneous constellation}

A constellation whose member spacecraft employ functional identical bus, payload, and operational characteristics (e.g., MMS and Iridium).

\section{Heterogeneous constellation}

A constellation whose member spacecraft employ different bus, payload, and operational characteristics.

\section{TAB 1.1.2 Formations}

\section{Formation Flying}

Two or more spacecraft that conduct a mission such that relative distances and 3D spatial relationships (i.e., distances and angles between all spacecraft) are controlled through direct sensing by one spacecraft of at least one other spacecraft state (e.g., GRACE).

\section{Reconfigurable formation}

A formation that possesses the ability to change one of more intrinsic characteristics while on orbit. Some of these characteristics may include any or all of the following changes: orbit, attitude, relative spacing, observing activity coordination with other spacecraft, number of spacecraft and other TBD characteristics.

\section{Homogeneous formation}

A formation whose member spacecraft employ functional identical bus, payload, and operational characteristics.

\section{Heterogeneous formation}

A formation whose member spacecraft employ different bus, payload, and operational characteristics.

\section{TAB 1.1.3 Fractionated}

\section{Fractionated spacecraft}

A fractionated spacecraft is a satellite architecture where the functional capabilities of a conventional monolithic spacecraft are distributed across multiple modules that are not structurally connected and interact through wireless links. These modules are capable of sharing their resources and using resources found elsewhere in the cluster. Unlike constellations and formations, the modules of a fractionated spacecraft are largely heterogeneous and perform distinct functions corresponding, e.g., to the various subsystem elements of a traditional satellite (e.g., DARPA F6 System).

Another taxonomy following these definitions looks into these categories in terms of characteristics and is shown in Table 2.

The main objectives of this study have been first to summarize what has been studied and developed previously in the domain of distributed missions, what is the state-of-the-art, who are the main players and what are the main challenges, and then to provide a preliminary characterization of the trade-offs that link science return and mission architectures. The outcomes of our study include a full terminology, a preliminary mission taxonomy, a survey of past, current and future DSM, examples of potential science applications, a list of technology challenges, and some preliminary results in developing DSM cost and risk analysis tools and are partially described in [6].

\section{PAST, CURRENT AND FUTURE DSM'S}

As part of the study, we collected data on 65 missions, past, current, in development, recommended with high priority, recommended with low priority and proposed concepts. In order to keep this list focused, we limited the future mission items to those that are mentioned in recent decadal studies or otherwise have broad community support.

The missions covered the 4 domains, Earth Science, Heliophysics, Astrophysics, and Planetary. Overall, the number of flight elements for the studied DSMs varies from 2 to 100. The most common type of mission was a heliophysics constellation of 2 to 6 identical, noninteracting spacecraft, making multipoint measurements from Earth orbit. When looking at the statistical distribution of the number of spacecraft for all missions, the mode was 2 , the median 3 and the average number is 11 , mainly due to the communications constellations and to the QB50 mission. When considering only the science missions, the average number of spacecraft per mission becomes 4.8 (including QB50) and 3.6 (without QB50). As stated above, heliophysics has almost half of all the DSM science concepts. $73 \%$ of the missions are real or likely to be implemented within about a decade and most missions are constellations where the spacecraft do not interact. 
Additionally, in order to identify future interest in DSM within the science community as well as potential DSM science applications, our team drafted a questionnaire and interviewed more than 50 Goddard scientists in the four science domains as well as in the Communications area. Results from the survey and the interviews will be summarized at the conference.

\section{A FEW EXAMPLES OF SPECIFIC GODDARD DSM PROJECTS}

At the end of the preliminary study, we identified 8 technology areas corresponding to DSM lifecycle:

1. Design and Development:

a. Pre-Phase A/Phase A DSM mission design tools

b. Prototyping \& Validation testbeds

c. Model-Based Engineering tools

2. Build and Manufacturing I\&T and Assembly:

a. Development and extension of standards

b. Integration and Testing (I\&T) frameworks

3. Launch and Development:

a. Low-thrust propulsion

b. Low-cost deployment multi-spacecraft systems

4. Communications:

a. High-speed spacecraft to spacecraft communications

b. Low-cost and fast SmallSats uplink/downlink

5. Operations and GN\&C:

a. Hardware and Software for autonomous sensing and control

b. Hardware and Software for Absolute and relative navigation

c. Hardware and Software for Coordinated pointing

6. Ground Data Processing:

a. Multi-spacecraft mission operation centers and ground data systems

b. Solutions for DSM "Big Data" operations challenge

7. Onboard Intelligence:

a. Onboard recognition of events of interest

b. Onboard goal-oriented planning and scheduling

c. Autonomous retargeting and reconfigurability

8. Science Data Processing

a. Scalable data management for large DSM

b. High accuracy multi-platform calibration, registration and fusion

Specific NASA Goddard projects are underway in several of these areas. More details will be be given at the conference on several of them, including the TradeSpace Analysis Tool for Constellation (TAT-C, Area 1), an I\&T framework (Area 2), multi-spacecraft mission operation centers (Area 6), as well as Onboard Intelligence and Science Data Processing (Areas $7 \& 8$ ). Additionally, current experiments are being conducted to integrate several of these capabilities that will enable a specific type of constellation, called Intelligent and Collaborative Constellations (ICCs). ICCs involve the combination of real-time data understanding, situational awareness, problem solving, planning and learning from experience, combined with communications and cooperation between multiple spacecraft in order to take full advantage of various sensors distributed on multiple platforms. Results of these recent and ongoing ICC experiments will also be presented at the conference.

\section{CONCLUSION}

This paper summarizes recent and ongoing work being conducted at Goddard in the area of Distributed Spacecraft Missions, and more particularly in the area of Constellations and Intelligent and Collaborative Constellations. Surveys, taxonomies and key technologies are identified; specific projects have been conducted to develop some of the main technologies that will be required to make future DSM a reality.

\section{ACKNOWLEDGEMENTS}

The author would like to thank all the members of the several Goddard study teams which produced the survey results, as well as the taxonomy and terminology definitions; this includes C. Adams, P. Dabney, M. Johnson, D. Leisawitz, F. Lemoine, S. Nag, W. Powell, D. Smith, K. Thome, S. Tompkins, and W. Wiscombe, as well as many others. She also would like to acknowledge the support of the Goddard Internal \& Research Development (IRAD) funding as well as of the Earth Science Technology Office (ESTO) Advanced Information Systems Technology (AIST) Program.

\section{REFERENCES}

[1] A. Barrett, "Multiple Platform Mission Taxonomy," JPL-CalTech Internal Report, Section 367, 2001.

[2] E. Torres-Martinez et al, "A Web of Sensors: Enabling the Earth Science Vision," Acta Astronautica, 3 (2003) 423-428.

[3] O.L. De Weck et al, "Staged deployment of communications satellite constellations in low earth orbit," J. Aerosp. Comput. Inf. Commun., Vol. 1, No. 3, pp. 119-136, 2004.

[4] P. Hildebrand et al, "Earth Science Vision 2030," NASA Working Group Report, March 2004, http://esto.nasa.gov/files/Earth Science Vision 2030.pdf.

[5] J. Esper et al, "Leonardo-BRDF: A New Generation Satellite Constellation." International Astronautical Congress, Rio de Janeiro, Brazil, 2000. http://ntrs.nasa.gov/search.jsp? $\mathrm{R}=20000105058$.

[6] J. Le Moigne et al, "Systems Architectures for Distributed Spacecraft Missions (DSM)", NASA HyspIRI Workshop, NASA Goddard Space Flight Center, Greenbelt, Maryland, June 4-6, 2014. 
Table 1 - DSM Terminology Taxonomy

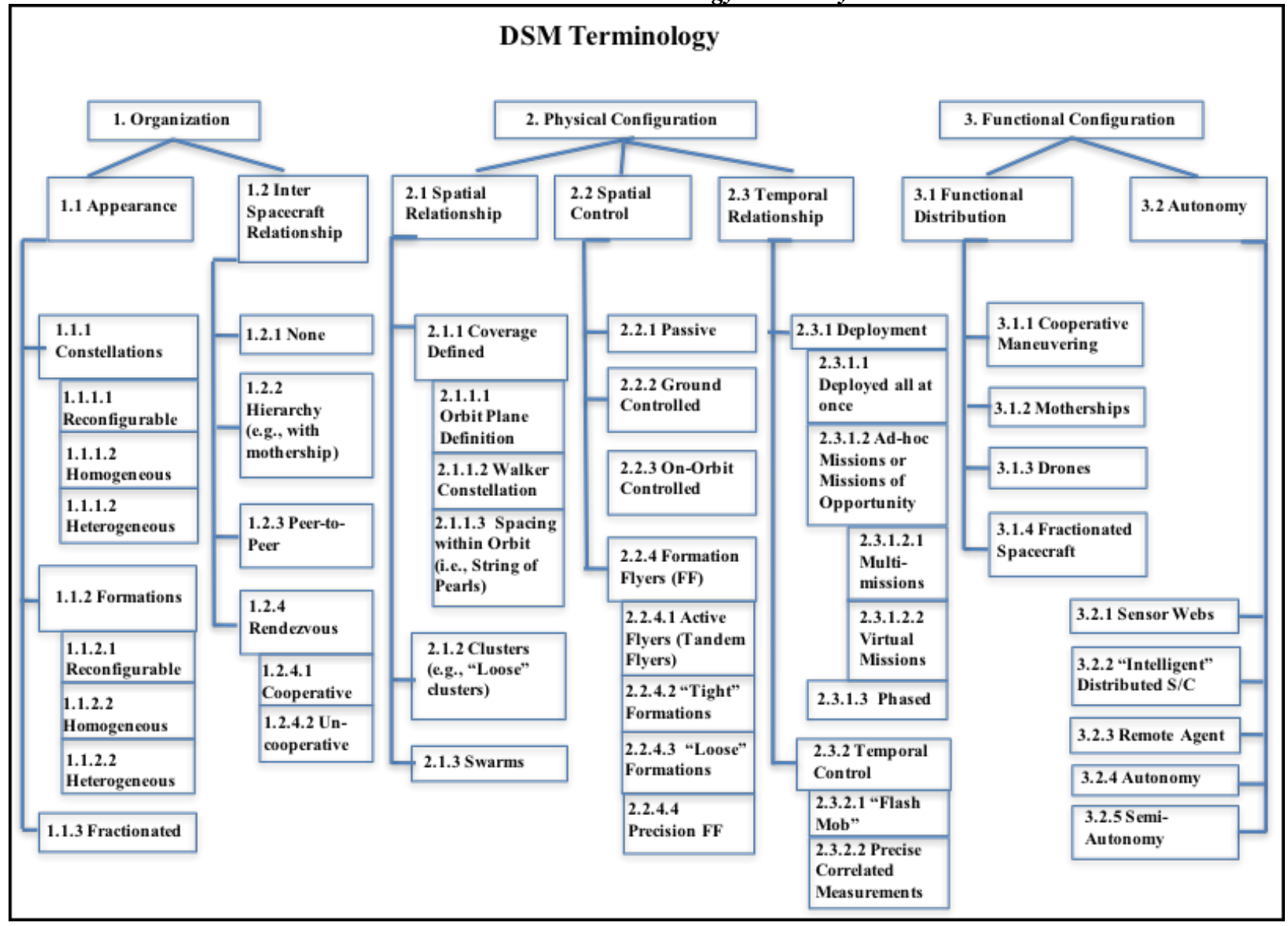

Table 2-DSM Characteristics Taxonomy

\begin{tabular}{|c|c|c|c|c|c|c|c|c|c|c|c|c|c|c|c|c|c|c|c|c|}
\hline \multirow{4}{*}{$\begin{array}{l}\text { CHARACTERISTICS } \\
\\
\text { Appearance and } \\
\text { Functionality }\end{array}$} & \multirow{4}{*}{\begin{tabular}{|l|} 
MONOL.ITHIC \\
Homogeneous \\
\end{tabular}} & \multicolumn{19}{|c|}{ DISTRIBUTED } \\
\hline & & \multicolumn{6}{|c|}{ CONSTELLATION } & \multicolumn{5}{|c|}{ FORMATION FLYING } & \multicolumn{4}{|c|}{ FRACTIONATED } & \multicolumn{4}{|c|}{ AD-HOCVIRTUAL MISSION } \\
\hline & & \multirow{2}{*}{\multicolumn{3}{|c|}{ Homogeneous }} & \multicolumn{3}{|c|}{ Heterogeneous } & \multirow{2}{*}{\multicolumn{2}{|c|}{ Homogeneous }} & \multicolumn{3}{|c|}{ Heterogeneous } & \multicolumn{4}{|c|}{ Heterogeneous } & \multicolumn{4}{|c|}{ Heterogeneous } \\
\hline & & & & & \multirow{2}{*}{\begin{tabular}{|c|}
$\begin{array}{c}\text { Instrume } \\
\text { nt }\end{array}$ \\
Swarm
\end{tabular}} & \multirow{2}{*}{\multicolumn{2}{|c|}{\begin{tabular}{l|c} 
Bus & Both \\
Reconfigurable
\end{tabular}}} & & & \multirow{2}{*}{\begin{tabular}{|c|}
$\begin{array}{c}\text { Instrume } \\
\text { nt }\end{array}$ \\
of Pearls
\end{tabular}} & \multirow{2}{*}{\multicolumn{2}{|c|}{\begin{tabular}{|l|l|} 
Bus & Both \\
Reconfigurable
\end{tabular}}} & \multicolumn{4}{|c|}{ Instrument and Bus } & \multicolumn{4}{|c|}{ Instrument and Bus } \\
\hline \multirow{3}{*}{\begin{tabular}{|c|} 
Spatial Relationship \\
Inter-Spacecraft \\
Relationship and \\
Functional Configuration
\end{tabular}} & N/A & $\begin{array}{c}\text { General/ } \\
\text { Variable } \\
\text { Ce. }\end{array}$ & \begin{tabular}{|c}
$\begin{array}{c}\text { String of } \\
\text { Pearls }\end{array}$ \\
\end{tabular} & Cluster & & & & $\begin{array}{c}\text { General/ } \\
\text { Variable } \\
\text { Ce.e. }\end{array}$ & String o & & & & & & & & $\begin{array}{r}\text { General/ } \\
(\mathrm{e.g.g}, \mathrm{m} \\
\text { orth }\end{array}$ & $\begin{array}{l}\begin{array}{l}\text { Variable } \\
\text { ultiple } \\
\text { (ts) }\end{array} \\
\end{array}$ & Strir & of Pearls \\
\hline & \multirow{2}{*}{ N/A } & \multirow{2}{*}{\multicolumn{2}{|c|}{ None }} & \multirow{2}{*}{$\begin{array}{c}\text { Hierachic } \\
\text { al }\end{array}$} & \multirow{3}{*}{\begin{tabular}{|c|}
$\begin{array}{c}\text { Peer-to- } \\
\text { Peer }\end{array}$ \\
\cline { 2 - 2 } On-Orbit \\
\end{tabular}} & \multicolumn{2}{|c|}{ Rendezveus } & & \multirow{2}{*}{\multicolumn{2}{|c|}{ Hierarchical }} & \multirow{2}{*}{\multicolumn{2}{|c|}{ Peer-to-Peer }} & \multirow{2}{*}{\multicolumn{2}{|c|}{ Hierarchical }} & \multirow{2}{*}{\multicolumn{2}{|c|}{ Peer-to-Peer }} & \multirow{2}{*}{\multicolumn{2}{|c|}{ None }} & & \\
\hline & & & & & & \begin{tabular}{|c|}
$\begin{array}{c}\text { Ceoperat } \\
\text { ive }\end{array}$ \\
\end{tabular} & \begin{tabular}{c|} 
Non- \\
Cooperati
\end{tabular} & None & & & & & & & & & & & & 10-Peer \\
\hline Spatial Control & \begin{tabular}{|c|}
$\begin{array}{c}\text { Ground and On- } \\
\text { Orbit }\end{array}$ \\
\end{tabular} & Passive & Gre & ound & & $\begin{array}{r}\text { Ground } \\
\text { Or }\end{array}$ & $\begin{array}{l}\text { and On- } \\
\text { bit }\end{array}$ & Ground & On-c & Orbit & $\begin{array}{r}\text { Ground } \\
\text { Or }\end{array}$ & $\begin{array}{l}1 \text { and } O n-~ \\
\text { rbit }\end{array}$ & & rbit & $\begin{array}{r}\text { Groun } \\
0 \\
\end{array}$ & and On- & Ground & On-c & rbit & \begin{tabular}{|l} 
Ground \\
and On- \\
Oetit-
\end{tabular} \\
\hline & & & & & & Incrementa & & & & & & & & & & & & & & \\
\hline Temporal Deployment & All at ence & & All at Once & & \begin{tabular}{|c|} 
By \\
Design
\end{tabular} & By Re. & action & & & All at Once & & & & & Once & & & Accret & onary & \\
\hline Autonomy & \begin{tabular}{|c|}
$\begin{array}{c}\text { None or Semi- } \\
\text { Autonomous }\end{array}$ \\
\end{tabular} & No & & Semi-Au & itonomy & Fully $A_{1}$ & utenomy & None & Semi-Au & utonomy & Fully $\mathrm{Al}$ & utenomy & None & Semi & tonomy & \begin{tabular}{|c|} 
Full \\
Autonom
\end{tabular} & No & & Semi & utonomy \\
\hline Number of Spacecraft & 1 & {$[2-1$} & 10] & [10- & & $>$ & 50 & & & [2-10] & & & & & & & {$[2-$} & & & $-50]$ \\
\hline Spacraft Mass (kg) & $\begin{array}{c}\text { Variable Size } \\
\text { and Mass }\end{array}$ & $<1$ & [1- & $-10 \mid$ & $|10-500|$ & $\begin{array}{l}500- \\
5000 \mid\end{array}$ & $>5000$ & {$[1-1$} & & |10-500| & $\begin{array}{l}500- \\
5000]\end{array}$ & $>5000$ & & & $\begin{array}{l}500- \\
5000 \mid\end{array}$ & $>5000$ & & ariable $\mathrm{Si}$ & and $\mathrm{x}$ & \\
\hline Launch Approach & Single & & All at Once & & $\mathrm{Mu}$ & Itiple Laun & ches & All at & Pnce & Mul & Itiple Laun & Iches & & & Once & & Indepet & ident and & Iultipl & aunches \\
\hline & & & & & Multiple & Launches & & & & Multiple & Launches & & & & & & & & & \\
\hline Launcher Approach & Dedicated & Dispe & nuser & \begin{tabular}{|c|} 
Dedicate \\
$\mathrm{d}$
\end{tabular} & \begin{tabular}{|c|} 
Rideshar \\
$\mathrm{e}$
\end{tabular} & \begin{tabular}{|c|}
$\begin{array}{c}\text { Hosted } \\
\text { Payloads }\end{array}$ \\
\end{tabular} & $\begin{array}{c}\text { Combinat } \\
\text { ion }\end{array}$ & Dispenser & $\begin{array}{c}\text { Dedicate } \\
\mathrm{d}\end{array}$ & \begin{tabular}{|c|} 
Rideshar \\
$\mathrm{e}$
\end{tabular} & \begin{tabular}{c|} 
Hosted \\
Payloads
\end{tabular} & $\begin{array}{c}\text { Combinati } \\
\text { on }\end{array}$ & & & & & & tabie/Miss & on dep & \\
\hline
\end{tabular}

